\title{
A novel candidate species of Anaplasma that infects avian erythrocytes
}

\author{
Ralph Eric Thijl Vanstreels ${ }^{1,2^{*}}$ D, Michael J. Yabsley ${ }^{3,4}$, Nola J. Parsons ${ }^{5}$, Liandrie Swanepoel ${ }^{4}$ and Pierre A. Pistorius ${ }^{1,2}$
}

\begin{abstract}
Background: Anaplasma spp. are Gram-negative obligate intracellular bacteria transmitted by ticks. Even though numerous studies have detected DNA from Anaplasma spp. in the blood of birds, thus far mammals were the only vertebrates demonstrated to serve as competent hosts to these organisms. We report a novel candidate species of Anasplasma that was associated with cytoplasmic inclusions in the erythrocytes of an African penguin (Spheniscus demersus) in South Africa.

Methods: Cytoplasmic inclusions were morphologically characterized from freshly-produced blood smears, and phylogenetic analysis of $16 \mathrm{~S} r R N A$ and groEL genes were used to evaluate the evolutionary relationships of the organism to other Anaplasmataceae.
\end{abstract}

Results: Dark-purple round or oval inclusions consistent with Anaplasmataceae morulae were observed in the cytoplasm of erythrocytes. Phylogenetic trees produced using different methods agreed that the organism detected in this study belongs to the genus Anaplasma, and suggested that it is most closely related to the cluster comprising $A$. centrale, $A$. capra, A. marginale and A. ovis. We propose provisionally naming the strain detected in this study as "Candidatus Anaplasma sphenisci".

Conclusions: This is the first species of Anaplasma shown to produce cytoplasmic inclusions in avian cells, opening the possibility that cytoplasmic inclusions in avian erythrocytes that had previously been attributed to Aegyptianella sp. might in fact correspond to Anaplasma. Further studies on the molecular biology of avian-infecting Anaplasmataceae will be valuable to provide insight into the evolution and epidemiology of these organisms.

Keywords: "Candidatus Anaplasma sphenisci", African penguin (Spheniscus demersus), Avian erythrocytes, South Africa, Phylogeny, 165 rRNA and groEL genes

\section{Background}

Anaplasmataceae (Alphaproteobacteria: Rickettsiales) are Gram-negative obligate intracellular bacteria found exclusively within membrane-bound inclusions or vacuoles in the cytoplasm of vertebrate and invertebrate host cells [1]. This family comprises five recognized genera (Aegyptianella, Anaplasma, Ehrlichia, Neorickettsia and Wolbachia) [1], and four candidate genera ("Candidatus Cryptoplasma", "Candidatus Neoehrlichia", "Candidatus Xenohaliotis", and "Candidatus Xenolissoclinum") [2-5].

\footnotetext{
* Correspondence: ralph_vanstreels@yahoo.com.br

${ }^{1}$ Marine Apex Predator Research Unit (MAPRU), Institute for Coastal and Marine Research, Nelson Mandela University, Port Elizabeth, South Africa ${ }^{2}$ DST/NRF Centre of Excellence at the Percy FitzPatrick Institute for African Ornithology, Department of Zoology, Nelson Mandela University, Port Elizabeth, South Africa

Full list of author information is available at the end of the article
}

The genus Anaplasma currently includes nine species, six candidate species as well as numerous unclassified species, all of which are either known or believed to be tick-borne (Table 1). Depending on the involved species, these organisms infect the cytoplasm of blood cells (erythrocytes, leukocytes or platelets), bone marrow precursor cells, or endothelial cells of vertebrates, forming pleomorphic clusters of bacteria (morulae) [6]. Mammals are the only vertebrates demonstrated thus far to be competent hosts of Anaplasma spp., but numerous studies have detected DNA from Anaplasma spp. (especially A. phagocytophilum) in the blood of birds and in the tissues of ticks collected from birds [7-11]. However, no studies demonstrated the presence of Anaplasma spp. cytoplasmic inclusions within blood cells of birds, and it was therefore considered unclear whether these organisms are able to

(C) The Author(s). 2018 Open Access This article is distributed under the terms of the Creative Commons Attribution 4.0 International License (http://creativecommons.org/licenses/by/4.0/), which permits unrestricted use, distribution, and reproduction in any medium, provided you give appropriate credit to the original author(s) and the source, provide a link to the Creative Commons license, and indicate if changes were made. The Creative Commons Public Domain Dedication waiver (http://creativecommons.org/publicdomain/zero/1.0/) applies to the data made available in this article, unless otherwise stated. 
Table 1 Overview of the species and candidate species of the genus Anaplasma [1, 41-54]

\begin{tabular}{|c|c|c|c|}
\hline Species & Tick host & Vertebrate host & Host cells \\
\hline Anaplasma bovis & $\begin{array}{l}\text { Haemaphysalis, Rhipicephalus, } \\
\text { Amblyomma }\end{array}$ & $\begin{array}{l}\text { Domestic and wild ruminants, } \\
\text { small mammals }\end{array}$ & Monocytes \\
\hline Anaplasma capra & Haemaphysalis & $\begin{array}{l}\text { Domestic and wild ruminants, } \\
\text { humans }\end{array}$ & Not known \\
\hline Anaplasma caudatum & Not known & Domestic and wild ruminants & Erythrocytes \\
\hline Anaplasma centrale & Ixodes, Haemaphysalis & Domestic and wild ruminants & Erythrocytes \\
\hline Anaplasma marginale & Ixodes, Dermacentor & Domestic ruminants & Erythrocytes \\
\hline Anaplasma odocoilei & Not known & Wild ruminants & Platelets \\
\hline Anaplasma ovis & $\begin{array}{l}\text { Dermacentor, Hyalomma, } \\
\text { Rhipicephalus }\end{array}$ & $\begin{array}{l}\text { Domestic and wild ruminants, } \\
\text { humans }\end{array}$ & Erythrocytes \\
\hline Anaplasma phagocytophilum & $\begin{array}{l}\text { Ixodes, Dermacentor, } \\
\text { Hyalomma, Rhipicephalus }\end{array}$ & $\begin{array}{l}\text { Domestic and wild ruminants, } \\
\text { horses, dogs, cats, rabbits, rodents, } \\
\text { insectivores, wild swine, humans }\end{array}$ & Granulocytes \\
\hline Anaplasma platys & Rhipicephalus & Dogs, camels & Platelets \\
\hline "Candidatus Anaplasma boleense" & Hyalomma & Not known & Not known \\
\hline "Candidatus Anaplasma camelii" & Not known & Camels & Not known \\
\hline "Candidatus Anaplasma corsicanum" & Not known & Domestic ruminants & Not known \\
\hline "Candidatus Anaplasma ivorensis" & Amblyomma & Not known & Not known \\
\hline "Candidatus Anaplasma mediterraneum" & Not known & Domestic ruminants & Not known \\
\hline "Candidatus Anaplasma rodmosense" & Not known & Rats & Not known \\
\hline "Candidatus Anaplasma sphenisci" & Not known & African penguins & Erythrocytes \\
\hline
\end{tabular}

${ }^{\text {a }}$ Proposed in this study

infect avian cells or merely remain viable in the avian plasma $[10,12]$.

On the other hand, cytoplasmic inclusions observed in the erythrocytes of birds have been traditionally attributed to members of the genus Aegyptianella. Currently the only recognized species of Aegyptianella is the avian-infecting Aegyptianella pullorum [13, 14], and the validity of other proposed Aegyptianella spp. remains unclear and the genus has been considered incertae sedis $[1,13,15]$. Aegyptianella pullorum infects the cytoplasm of erythrocytes forming pleomorphic inclusions with a diameter ranging between $0.3-4.0 \mu \mathrm{m}$, and has been demonstrated to infect chickens, turkeys, ducks, geese and quails [13, 16, 17]. A previous genetic study revealed that Ae. pullorum from turkeys is closely related to Anaplasma [17], leading some authors to suggest that Ae. pullorum should be reclassified as an Anaplasma $[18,19]$, but currently there is no consensus on this suggestion [20].

In this study, we describe a novel candidate species of Anaplasma that is associated with cytoplasmic inclusions in the erythrocytes of the African penguin (Spheniscus demersus), and discuss the phylogenetic relationships of this organism to other Anaplasmataceae.

\section{Methods}

The Southern African Foundation for the Conservation of Coastal Birds (SANCCOB) facility in Cape Town $\left(33^{\circ} 50^{\prime} 02^{\prime \prime} \mathrm{S} 18^{\circ} 29^{\prime} 29^{\prime \prime} \mathrm{E}\right)$ receives and rehabilitates oiled, sick, and injured marine and coastal birds along the coast of South Africa. Cytoplasmic inclusions consistent with Anasplasmataceae were observed in the erythrocytes of an adult African penguin during the examination of blood smears as a part of routine veterinary checks. The individual history of the studied penguin is summarized in Additional file 1.

Blood was obtained from the tarsal vein and thin blood smears were freshly prepared, fixed and stained with a modified Wright-Giemsa stain (Kyro-Quick, Kyron Laboratories, Benrose, South Africa). The percentage of erythrocytes with inclusions was estimated with manual counts of erythrocytic inclusions and software-assisted counts of $c .2000$ erythrocytes; erythrocytes were counted from photographs of 20 randomly-selected microscope fields under 1000× magnification using ImageJ $1.46 \mathrm{r}$ [21, 22]. ImageJ $1.46 \mathrm{r}$ was also used to measure the width of cytoplasmic inclusions. The following morphological characteristics were recorded for 100 erythrocytic inclusions: position (polar, subpolar, median), contact with host cell margins (contact with outer margin, contact with nuclear margin, no contact with margins), and the presence of adjacent indentation of host cell outer margin (present, absent).

DNA was extracted from frozen blood using the DNeasy Blood and Tissue kit (Qiagen, Hilden, Germany) 
following the manufacturer's instructions. A $927 \mathrm{bp}$ segment of the 16S rRNA gene was amplified using the primers $8 \mathrm{~F}$ and $1492 \mathrm{R}$ [23]. A 939 bp segment of the groEL gene was amplified using a nested PCR with the primary primers HS1 and HS6 and secondary primers HS43 and HSVR [24, 25]. Amplification products were sequenced using Sanger bidirectional sequencing.

MegaBLAST [26] was used to identify publicly-available sequences that were highly similar to those obtained in this study. Phylogenetic analyses of the $16 S$ rRNA and groEL genes were conducted to compare sequences obtained in this study to publicly-available sequences of Anaplasmataceae (Additional file 2: Table S1). Sequences were aligned using ClustalW [27] as implemented in MEGA 7 [28]. General Time Reversible model with invariant sites and gamma distribution $(\mathrm{GTR}+\mathrm{I}+\mathrm{G})$ was used for both genes as recommended by jModelTest 2.1.10 [29]. Neighbor-Joining trees (maximum composite likelihood, including transitions and transversions) and Maximum Likelihood trees (nearest neighbor interchange) were produced using MEGA 7; bootstrap values were calculated from 5000 replicates. Bayesian trees (two simultaneous Markov chains, 5 million generations, sampling every 1000 generations) were produced using MrBayes 3.2.6 [30]; posterior probabilities were calculated after discarding the first $25 \%$ trees as a 'burn-in' step. Phylogenetic analyses were conducted separately for each gene and also for concatenated (Neighbor-Joining and Maximum Likelihood) or partitioned (Bayesian) sequences of the two genes.

\section{Results}

Dark-purple round or oval inclusions consistent with Anaplasmataceae morulae were observed in the cytoplasm of $0.10 \%$ of the erythrocytes (Fig. 1). In most cases these inclusions had a dense and homogeneous texture with a slightly paler center (e.g. Fig. 1f), but in some cases it was possible to identify irregularly distributed dense dots or crescent-shaped areas (e.g. Fig $1 j$ and 11 ). The inclusions $(n=100)$ had a width of $2.28 \pm 0.56 \mu \mathrm{m}$ (range: $1.02-3.33 \mu \mathrm{m}$ ), and were positioned as follows: 46\% polar (e.g. Fig. 1g), 39\% subpolar (e.g. Fig. 1k), and $15 \%$ median (e.g. Fig. 1d). Most of the inclusions (75\%) appeared to be in contact with the outer margins of the host cell (e.g. Fig. 1j), 7\% appeared to be in contact with the host cell nucleus (e.g. Fig. 11), and 18\% did not appear to be in direct contact with any host cell margins (e.g. Fig. 1e). The outer margins of the host cell were deformed and a small indentation was visible in $63 \%$ of the erythrocytes where inclusions were in direct contact with the host cell outer margin (e.g. Fig. 1d and i). In addition to the erythrocytic inclusions, one lymphocyte contained dark-purple cytoplasmic inclusions (Additional file 3: Figure S1); however, despite extensive searching (> 1000 leukocytes examined), no other leukocytes or thrombocytes were seen with similar cytoplasmic inclusions and it was therefore not possible to determine the identity of these structures.

Molecular detection of $16 S$ rRNA and groEL sequences confirmed the presence of an organism belonging to Anaplasmataceae. MegaBLAST found that the closest publicly-available sequences were $A$. marginale (Genbank KU686794) with 96.8\% sequence identity for the $16 S$ rRNA gene and A. phagocytophilum (CP015376) with 78.7\% sequence identity for the groEL gene. Relative to publicly-available sequences of A. pullorum, sequence identity was $89.1 \%$ for the $16 \mathrm{~S}$ rRNA gene and $76.3 \%$ for the groEL gene. Phylogenetic trees of the $16 S$ rRNA and groEL sequences differed in relation to the topology (Fig. 2, Additional file 4: Figure S2), but the different phylogenetic methods agreed that the organism detected in this study belongs to the genus Anaplasma, and that it is most closely related to the cluster comprising A. centrale, A. capra, A. marginale and A. ovis.

\section{Discussion}

Considering the host species and the phylogenetic relationship to other Anaplasma species, we propose provisionally naming the bacterial strain detected in this study as "Candidatus Anaplasma sphenisci" (derived from Spheniscidae, the family of the penguin host).

The finding that mammals are not the only vertebrate hosts of Anaplasma advances the question of whether Aegyptianella pullorum should be reclassified as Anaplasma pullorum. Our phylogenetic analyses agree that Ae. pullorum, Anaplasma spp. and "Candidatus Cryptoplasma californiense" are monophyletic; however, different phylogenetic methods disagree on the relationships amongst these groups (see Fig. 2 and Additional file 4: Figure S2). In the absence of additional information on the genetic diversity of other avian-infecting Anaplasmataceae, the question whether the reclassification of $A e$. pullorum is warranted remains unresolved.

The fact that Anaplasmataceae-like cytoplasmic inclusions have also been recorded in the erythrocytes of numerous other avian species (e.g. doves, cranes, kites, pheasants, psittacines and passerines) [13,31-33] suggests that other species of avian-infecting Anaplasmataceae may exist but have yet to be described. This seems particularly plausible in the case of the intraerythrocytic inclusions originally described as "Aegyptianella botuliformis" [31] and "Aegyptianella minutus" [32], both of which produce erythrocytic inclusions that are morphologically distinct from those traditionally attributed to Ae. pullorum. Similarly, the Rickettsiales-like cytoplasmic inclusions observed in the erythrocytes of a king penguin (Aptenodytes patagonicus) that died while in care at SANCCOB [34] appeared distinct from those observed in this study (smaller, finer structure, 


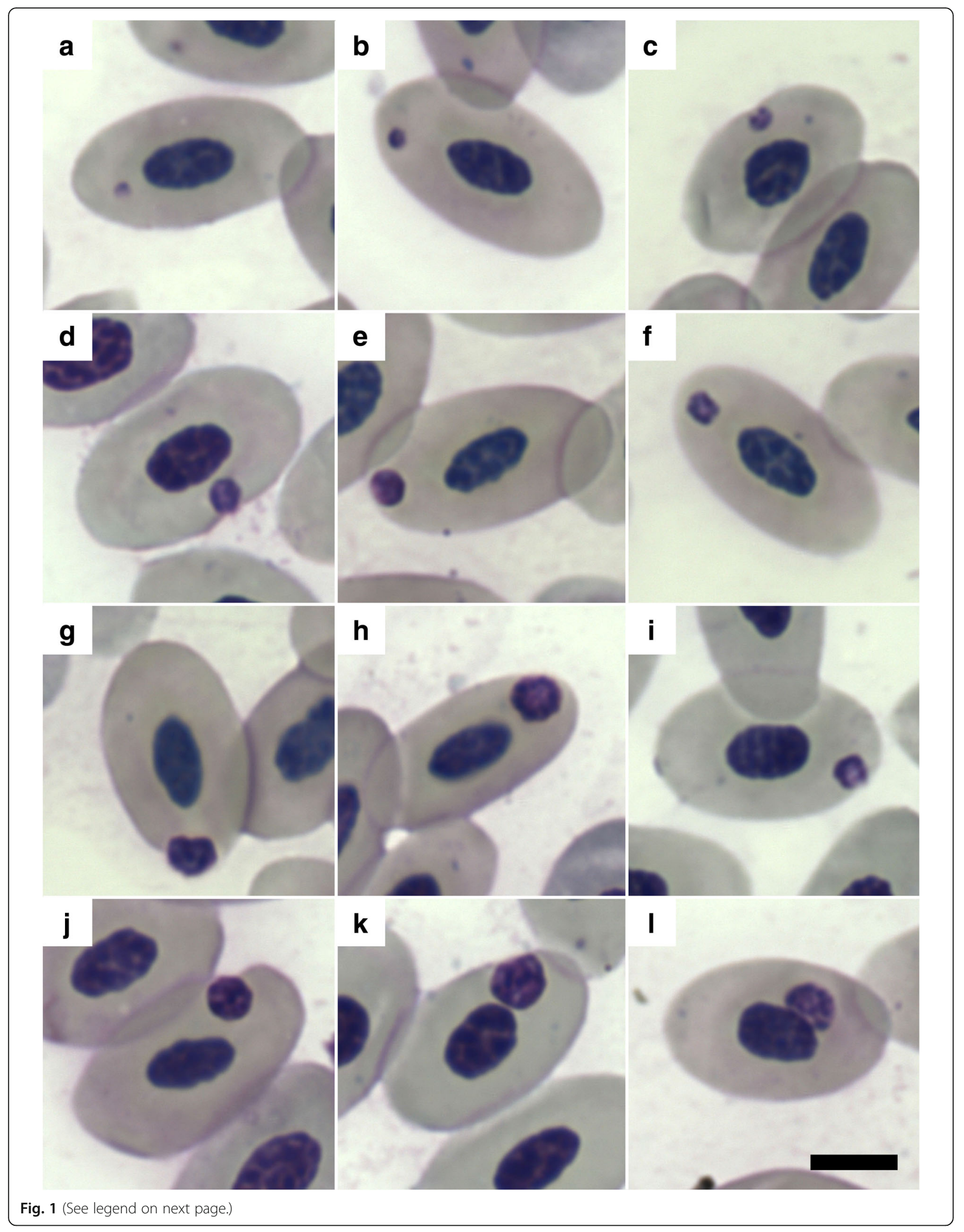


(See figure on previous page.)

Fig. 1 Cytoplasmic inclusions attributed to "Candidatus Anaplasma sphenisci" in the erythrocytes of an African penguin (Spheniscus demersus). Modified Wright-Giemsa stain. Inclusions ranged in size from small dots $(\mathbf{a}, \mathbf{b})$ to pleomorphic structures that were smaller than the host cell nucleus (c-I) and were

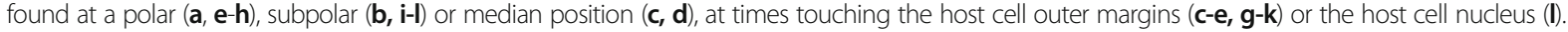
scale-bar: 5 m

with pale central vacuoles, more clearly-defined dark purple dots, did not distort the outer margin of the host cell) and likely also represent a distinct (and potentially novel) organism. Future studies on the molecular biology of avian-infecting Anaplasmataceae will therefore be valuable to provide insight into the evolution of these organisms and indicate the most appropriate nomenclature for Aegyptianella.

Over the past few decades, tens of thousands of blood smears from African penguins have been examined at

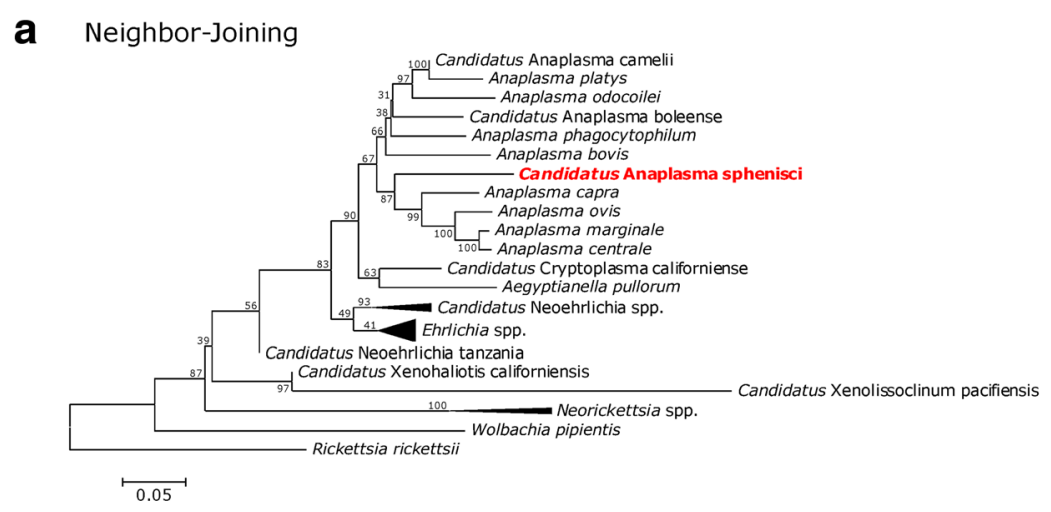

b Maximum Likelihood

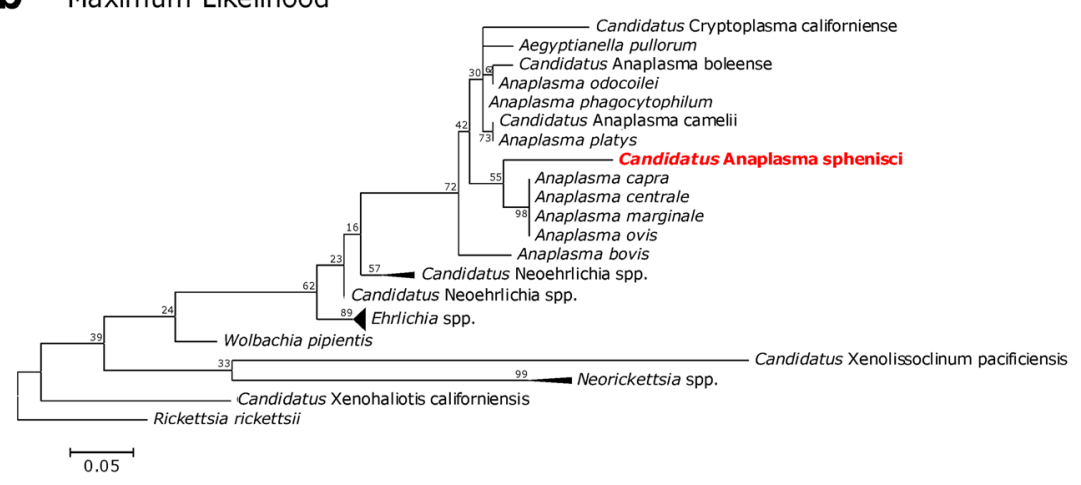

C Bayesian inference

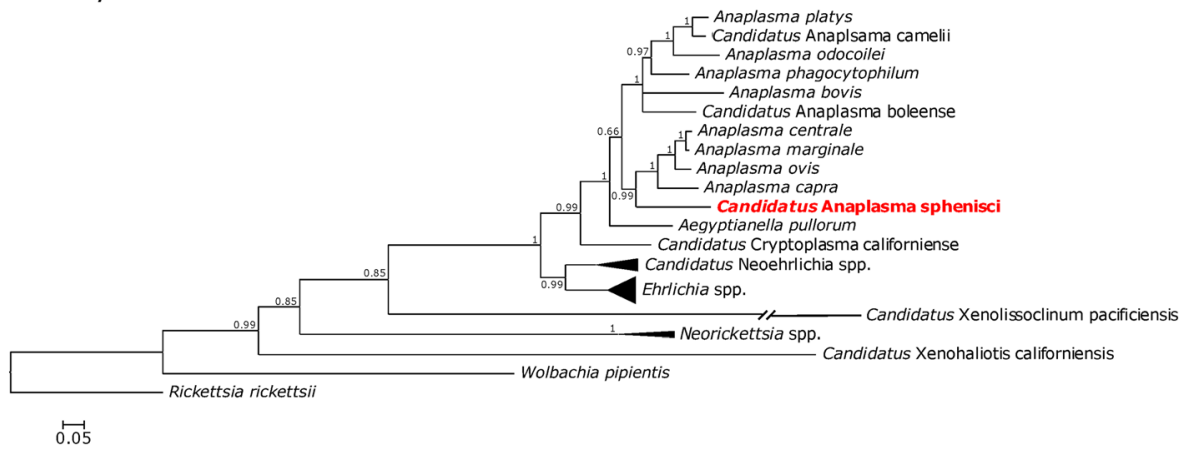

Fig. 2 Phylogenetic relationships of "Candidatus Anaplasma sphenisci" as determined by different phylogenetic methods based on partial sequences of the 165 rRNA and groEL genes. Branch lengths are drawn proportionally to evolutionary distance (scale-bars are shown). Numbers adjacent to nodes indicate bootstrap values $(\mathbf{a}, \mathbf{b})$ or posterior probabilities (c) 
SANCCOB. However, because "Candidatus Anaplasma sphenisci" was not known to exist, it is possible that its inclusions were mistakenly interpreted as corresponding to small round forms of Babesia spp., degenerative changes, or staining artifacts. Our results therefore do not necessarily indicate that this is a novel or emerging pathogen, and further studies will be necessary to evaluate its prevalence in African penguins.

The vectors of "Candidatus Anaplasma sphenisci" are not known. The soft tick Ornithodoros capensis is a common parasite of African penguins, including in South Africa [35], and is thus the most probable vector. However, the hard tick Ixodes uriae is also thought to occur on the coast of South Africa and, even though it has not yet been recorded on African penguins, it is a frequent parasite of other penguin species elsewhere [36]. Both O. capensis and I. uriae are shared by a large number of seabird species [37], including seabirds that breed sympatrically with African penguins such as Bank and Cape cormorants (Phalacrocorax neglectus and Phalacrocorax capensis), Cape gannets (Morus capensis) and Kelp gulls (Larus dominicanus) [38-40]. The potential therefore exists for the transmission of this bacterium to other seabird species.

\section{Conclusions}

"Candidatus Anaplasma sphenisci" is the first species candidate of Anaplasma shown to produce cytoplasmic inclusions in avian cells. This opens the possibility that cytoplasmic inclusions in avian erythrocytes that had previously been attributed to Aegyptianella sp. might in fact correspond to Anaplasma. It is therefore clear that the diversity and host range of Anaplasma spp. might have been underestimated, and further studies on the molecular biology of avian-infecting Anaplasmataceae will be valuable to provide insight into the evolution and epidemiology of these organisms.

\section{Additional files}

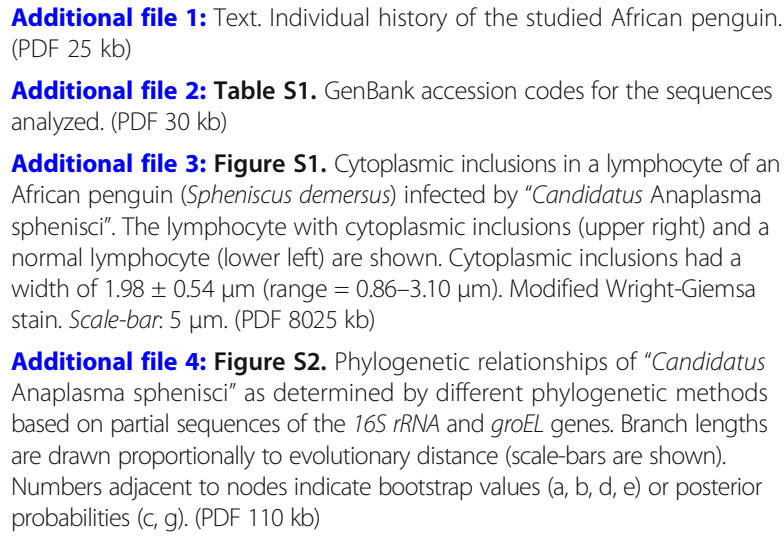

Additional file 2: Table S1. GenBank accession codes for the sequences analyzed. (PDF $30 \mathrm{~kb}$ )

Additional file 3: Figure S1. Cytoplasmic inclusions in a lymphocyte of an African penguin (Spheniscus demersus) infected by "Candidatus Anaplasma sphenisci". The lymphocyte with cytoplasmic inclusions (upper right) and a normal lymphocyte (lower left) are shown. Cytoplasmic inclusions had a width of $1.98 \pm 0.54 \mu \mathrm{m}$ (range $=0.86-3.10 \mu \mathrm{m})$. Modified Wright-Giemsa stain. Scale-bar: 5 mm. (PDF 8025 kb)

Additional file 4: Figure S2. Phylogenetic relationships of "Candidatus Anaplasma sphenisci" as determined by different phylogenetic methods based on partial sequences of the 16S rRNA and groEL genes. Branch lengths are drawn proportionally to evolutionary distance (scale-bars are shown). Numbers adjacent to nodes indicate bootstrap values $(a, b, d, e)$ or posterior probabilities (c, g). (PDF $110 \mathrm{~kb})$

\section{Abbreviations}

PCR: polymerase chain reaction; SANCCOB: Southern African Foundation for the Conservation of Coastal Birds

\section{Acknowledgements}

We wish to thank the many staff, collaborators and volunteers at SANCCOB, especially Natasha Ayres, Renata Hurtado, and Katrin Ludynia.

\section{Funding}

SANCCOB is supported by a wide range of local and international donors including international zoos and aquaria, foundations and trusts, corporates and individuals. This research was supported by the National Research Foundation and by state and federal supporters of the Southeastern Cooperative Wildlife Disease Study.

\section{Availability of data and materials}

Gene sequences obtained in this study were deposited in GenBank (accession numbers MG748724 and MG748859). Blood smears and ethanol-preserved aliquots of the same blood sample were deposited in the collection of the International Reference Centre for Avian Haematozoa (IRCAH), Queensland, Australia (accession codes G466205 and G466206). Other relevant data are provided in the additional files.

\section{Authors' contributions}

RETV and PAP were responsible for the study coordination. RETV and NJP collected the samples and evaluated blood smears. MJY and LS conducted molecular analyses. RETV, MJY and NJP drafted and LS and PAP edited the manuscript. All authors read and approved the final manuscript.

\section{Ethics approval}

This study was conducted under annual permits from the Department of Environmental Affairs (RES2016/18, RES2017/56) and under the approval of the University of Cape Town Animal Ethics Committee (2014/V18/SCNP2).

Consent for publication

Not applicable.

\section{Competing interests}

The authors declare that they have no competing interests.

\section{Publisher's Note}

Springer Nature remains neutral with regard to jurisdictional claims in published maps and institutional affiliations.

\section{Author details}

${ }^{1}$ Marine Apex Predator Research Unit (MAPRU), Institute for Coastal and Marine Research, Nelson Mandela University, Port Elizabeth, South Africa. ${ }^{2}$ DST/NRF Centre of Excellence at the Percy FitzPatrick Institute for African Ornithology, Department of Zoology, Nelson Mandela University, Port Elizabeth, South Africa. ${ }^{3}$ Warnell School of Forestry and Natural Resources, The University of Georgia, Athens, GA, USA. ${ }^{4}$ Southeastern Cooperative Wildlife Disease Study, Department of Population Health, College of Veterinary Medicine, The University of Georgia, Athens, GA, USA. ${ }^{5}$ Southern African Foundation for the Conservation of Coastal Birds (SANCCOB), Cape Town, South Africa.

Received: 9 July 2018 Accepted: 30 August 2018

Published online: 24 September 2018

\section{References}

1. Dumler JS, Barbet AF, Bekker C, Dasch GA, Palmer GH, Ray SC, et al. Reorganization of genera in the families Rickettsiaceae and Anaplasmataceae in the order Rickettsiales: unification of some species of Ehrlichia with Anaplasma, Cowdria with Ehrlichia and Ehrlichia with Neorickettsia, descriptions of six new species combinations and designation of Ehrlichia equi and "HGE agent" as subjective synonyms of Ehrlichia phagocytophila. Int J Syst Evol Microbiol. 2001; 51:2145-65.

2. Cicala F, Moore JD, Cáceres-Martínez J, Del Río-Portilla MA, Hernández-Rodríguez $M$, Vásquez-Yeomans $R$, et al. Multigenetic characterization of 'Candidatus Xenohaliotis californiensis'. Int J Syst Evol Microbiol. 2017;67:42-9. 
3. Eshoo MW, Carolan HE, Massire C, Chou DM, Crowder CD, Rounds MA, et al. Survey of Ixodes pacificus ticks in California reveals a diversity of microorganisms and a novel and widespread Anaplasmataceae species. PLoS One. 2015;10:e0135828.

4. Kawahara M, Rikihisa Y, Isogai E, Takahashi M, Misumi H, Suto C, et al. Ultrastructure and phylogenetic analysis of 'Candidatus Neoehrlichia mikurensis' in the family Anaplasmataceae, isolated from wild rats and found in Ixodes ovatus ticks. Int J Syst Evol Microbiol. 2004;54:1837-43.

5. Kwan JC, Schmidt EW. Bacterial endosymbiosis in a chordate host: long-term coevolution and conservation of secondary metabolism. PLoS One. 2013;8:e80822.

6. Rikihisa Y. The tribe Ehrlichieae and ehrlichial diseases. Clin Microbiol Rev. 1991;4:286-308.

7. Skotarczak B, Rymaszewska A, Wodecka B, Sawczuk M, Adamska M, Maciejewska A. PCR detection of granulocytic Anaplasma and Babesia in Ixodes ricinus ticks and birds in west-central Poland. Ann Agric Environ Med. 2006;13:21-3.

8. Ogden NH, Lindsay LR, Hanincova K, Barker IK, Bigras-Poulin M, Charron DF, et al. Role of migratory birds in introduction and range expansion of Ixodes scapularis ticks and of Borrelia burgdorferi and Anaplasma phagocytophilum in Canada. Appl Environ Microbiol. 2008;74:1780-90.

9. loannou I, Chochlakis D, Kasinis N, Anayiotos P, Lyssandrou A, Papadopoulos B, et al. Carriage of Rickettsia spp., Coxiella burnetii and Anaplasma spp. by endemic and migratory wild birds and their ectoparasites in Cyprus. Clin Microbiol Infect. 2009;15:158-60.

10. Keesing F, Hersh MH, Tibbetts M, McHenry DJ, Duerr S, Brunner J, et al. Reservoir competence of vertebrate hosts for Anaplasma phagocytophilum. Emerg Infect Dis. 2012;18:2013-6.

11. Dingler RJ, Wright SA, Donohue AM, Macedo PA, Foley JE. Surveillance for Ixodes pacificus and the tick-borne pathogens Anaplasma phagocytophilum and Borrelia burgdorferi in birds from California's Inner Coast Range. Ticks Tick-Borne Dis. 2014;5:436-45.

12. Johnston E, Tsao Jl, Muñoz JD, Owen J. Anaplasma phagocytophilum infection in American robins and gray catbirds: an assessment of reservoir competence and disease in captive wildlife. J Med Entomol. 2013;50:163-70.

13. Gothe R. Aegyptianella: an appraisal of species, systematics, avian hosts, distribution, and developmental biology in vertebrates and vectors and epidemiology. In: Harris KF, editor. Advances in Disease Vector Research. New York: Springer; 1992. p. 67-100.

14. Zhang C, Rikihisa Y. Proposal to transfer 'Aegyptianella ranarum', an intracellular bacterium of frog red blood cells, to the family Flavobacteriaceae as 'Candidatus Hemobacterium ranarum' comb. nov. Environ Microbiol. 2004;6:568-73.

15. Rikihisa Y. New findings on members of the family Anaplasmataceae of veterinary importance. Ann N Y Acad Sci. 2006;1078:438-45.

16. Castle MD, Christensen BM. Isolation and identification of Aegyptianella pullorum (Rickettsiales, Anaplasmataceae) in wild turkeys from North America. Avian Dis. 1985;29:437-45.

17. Rikihisa Y, Zhang C, Christensen BM. Molecular characterization of Aegyptianella pullorum (Rickettsiales, Anaplasmataceae). J Clin Microbiol. 2003;41:5294-7.

18. Deplazes P, Eckert J, von Samson-Himmelstjerna G, Zahner H. Lehrbuch der Parasitologie für die Tiermedizin. Stuttgart: Georg Thieme Verlag; 2012.

19. Kocan K, De La Fuente J, Cabezas-Cruz A. The genus Anaplasma: new challenges after reclassification. Rev Sci Tech Int Off Epizoot. 2015;34:577-86.

20. Rikihisa Y, Kreier JP. Incertae Sedis V. Aegyptianella. In: Whitman WB, Rainey F, Kämpfer P, Trujillo M, Chun J, DeVos P, Hedlund B, Dedysh S, editors. Bergey's Manual of Systematics of Archaea and Bacteria. Baltimore: Wiley; 2015.

21. Gering $E$, Atkinson CT. A rapid method for counting nucleated erythrocytes on stained blood smears by digital image analysis. J Parasitol. 2004;90:879-81.

22. Schneider CA, Rasband WS, Eliceiri KW. NIH Image to ImageJ: 25 years of image analysis. Nat Methods. 2012;9:671-5.

23. Weisburg WG, Barns SM, Pelletier DA, Lane DJ. 165 ribosomal DNA amplification for phylogenetic study. J Bacteriol. 1991;173:697-703.

24. Sumner JW, Nicholson WL, Massung RF. PCR amplification and comparison of nucleotide sequences from the groESL heat shock operon of Ehrlichia species. J Clin Microbiol. 1997;35:2087-92.

25. Petrovec M, Sumner J, Nicholson W, Childs J, Strle F, Barlič J, et al. Identity of ehrlichial DNA sequences derived from Ixodes ricinus ticks with those obtained from patients with human granulocytic ehrlichiosis in Slovenia. J Clin Microbiol. 1999;37:209-10.

26. Morgulis A, Coulouris G, Raytselis Y, Madden TL, Agarwala R, Schäffer AA. Database indexing for production MegaBLAST searches. Bioinformatics. 2008;24:1757-64.
27. Thompson JD, Gibson T, Higgins DG. Multiple sequence alignment using ClustalW and ClustalX. Curr Protoc Bioinforma. 2002:00(2.3):2.3.1-2.3.22.

28. Kumar S, Stecher G, Tamura K. MEGA7: Molecular Evolutionary Genetics Analysis version 7.0 for bigger datasets. Mol Biol Evol. 2016;33:1870-4.

29. Darriba D, Taboada GL, Doallo R, Posada D. jModelTest 2: more models, new heuristics and parallel computing. Nat Methods. 2012;9:772.

30. Ronquist F, Teslenko M, Van Der Mark P, Ayres DL, Darling A, Höhna S, et al. MrBayes 3.2: efficient Bayesian phylogenetic inference and model choice across a large model space. Syst Biol. 2012;61:539-42.

31. Huchzermeyer F, Horak I, Putterill J, Earle R. Description of Aegyptianella botuliformis n. sp. (Rickettsiales: Anaplasmataceae) from the helmeted guineafowl, Numida meleagris. Onderstepoort J Vet Res. 1992;59:97-101.

32. Peirce M. A new species of Aegyptianella from south-east Asia. Vet Rec. 1999;145:288.

33. Peirce M. A taxonomic review of avian piroplasms of the genus Babesia Starcovici, 1893 (Apicomplexa: Piroplasmorida: Babesiidae). J Nat Hist. 2000;34:317-32.

34. Parsons NJ, Gous TA, Cranfield MR, Cheng LI, Schultz A, Horne E, et al. Novel vagrant records and occurrence of vector-borne pathogens in King penguins (Aptenodytes patagonicus) in South Africa. Polar Biol. 2018;41:79-86.

35. Daturi A. A preliminary study of tick populations in jackass penguin nests on Marcus Island, South Africa. Ostrich. 1986;57:95-100.

36. Muñoz-Leal S, González-Acuña D. The tick Ixodes uriae (Acari: Ixodidae): hosts, geographical distribution, and vector roles. Ticks Tick-Borne Dis. 2015;6:843-68.

37. Dietrich M, Gómez-Díaz E, McCoy KD. Worldwide distribution and diversity of seabird ticks: implications for the ecology and epidemiology of tickborne pathogens. Vector-Borne Zoonotic Dis. 2011;11:453-70.

38. Theiler G. African ticks and birds. Ostrich. 1959;30:353-78.

39. Williams A. Nests and cormorant biology. Cormorant. 1978;4:22-7.

40. Cooper J. Biology of the bank cormorant, part 4: nest construction and characteristics. Ostrich. 1986;57:170-9.

41. Kawahara M, Rikihisa Y, Lin Q, Isogai E, Tahara K, Itagaki A, et al. Novel genetic variants of Anaplasma phagocytophilum, Anaplasma bovis, Anaplasma centrale, and a novel Ehrlichia sp. in wild deer and ticks on two major islands in Japan. Appl Environ Microbiol. 2006;72:1102-9.

42. Rymaszewska A, Grenda S. Bacteria of the genus Anaplasma - characteristics of Anaplasma and their vectors: a review. Vet Med (Praha). 2008;53:573-84.

43. Chochlakis D, loannou I, Tselentis Y, Psaroulaki A. Human anaplasmosis and Anaplasma ovis variant. Emerg Infect Dis. 2010;16:1031-2.

44. Rar V, Golovljova I. Anaplasma, Ehrlichia, and "Candidatus Neoehrlichia" bacteria: pathogenicity, biodiversity, and molecular genetic characteristics, a review. Infect Genet Evol. 2011;11:1842-61.

45. Stuen S, Granquist EG, Silaghi C. Anaplasma phagocytophilum - a widespread multi-host pathogen with highly adaptive strategies. Front Cell Infect Microbiol. 2013;3:31.

46. Tate CM, Howerth EW, Mead DG, Dugan VG, Luttrell MP, Sahora Al, et al. Anaplasma odocoilei sp. nov. (family Anaplasmataceae) from white-tailed deer (Odocoileus virginianus). Ticks Tick-Borne Dis. 2013;4:110-9.

47. Bastos AD, Mohammed OB, Bennett NC, Petevinos C, Alagaili AN. Molecular detection of novel Anaplasmataceae closely related to Anaplasma platys and Ehrlichia canis in the dromedary camel (Camelus dromedarius). Vet Microbiol. 2015;179:310-4.

48. Belkahia H, Said MB, Sayahi L, Alberti A, Messadi L. Detection of novel strains genetically related to Anaplasma platys in Tunisian one-humped camels (Camelus dromedarius). J Infect Dev Ctries. 2015;9:1117-25.

49. Li H, Zheng Y-C, Ma L, Jia N, Jiang B-G, Jiang R-R, et al. Human infection with a novel tick-borne Anaplasma species in China: a surveillance study. Lancet Infect Dis. 2015;15:663-70.

50. Li Y, Chen Z, Liu Z, Liu J, Yang J, Li Q, et al. Molecular survey of Anaplasma and Ehrlichia of red deer and sika deer in Gansu, China in 2013. Transbound Emerg Dis. 2016;63:e228-36.

51. Ehounoud CB, Yao KP, Dahmani M, Achi YL, Amanzougaghene N, N'Douba AK, et al. Multiple pathogens including potential new species in tick vectors in Côte d'Ivoire. PLoS Negl Trop Dis. 2016;10:e0004367.

52. Guo W-P, Tian J-H, Lin X-D, Ni X-B, Chen X-P, Liao Y, et al. Extensive genetic diversity of Rickettsiales bacteria in multiple mosquito species. Sci Rep. 2016;6:38770.

53. Dahmani M, Davoust B, Tahir D, Raoult D, Fenollar F, Mediannikov O. Molecular investigation and phylogeny of Anaplasmataceae species infecting domestic animals and ticks in Corsica, France. Parasit Vectors. 2017;10:302.

54. Qin X, Han F, Luo L, Zhao F, Han H, Zhang Z, et al. Anaplasma species detected in Haemaphysalis longicornis tick from China. Ticks Tick-Borne Dis. 2018;9:840-3. 